\title{
Prevalence of perceived coercion among psychiatric patients: literature review and meta-regression modelling
}

Giles Newton-Howes, ${ }^{1,2}$ James Stanley ${ }^{2}$

The Psychiatrist (2012), 36, 335-340, doi: 10.1192/pb.bp.111.037358

${ }^{1}$ Imperial College London, UK; ${ }^{2}$ Otago University, Wellington, New Zealand

Correspondence to

Giles Netwon-Howes

(giles.newton-howes@imperial.ac.uk)

First received 25 Oct 2011, final revision 1 Feb 2012, accepted 29 Feb 2012
Aims and method To assess how common the subjective experience of coercion is in psychiatric care and what affects its prevalence. A review of published data was undertaken to assess prevalence of coercion and potential confounding variables. The heterogeneity of results was studied using meta-regression to quantify the relative impact of four potential explanatory variables.

Results The raw prevalence of perceived coercion ranged from 16 to $90 \%$. A quarter of legally detained patients did not feel coerced into psychiatric care, whereas a quarter of voluntary in-patients reported coercion in care. Coercion was more common in studies outside the USA, among patient populations subject to legal detention and populations studied using the MacArthur Perceived Coercion Scale as opposed to other measures. Timing of the interview was not associated with coercion.

Clinical implications Coercion in psychiatric care remains highly prevalent but varies widely by study. Consistency in measurement is necessary to allow better comparison between studies.

Declaration of interest None.
Perceived coercion in care is an issue of particular importance in psychiatry, partly due to the growing use of interventions that intuitively increase the likelihood of this occurring. ${ }^{1}$ The most obvious example of actions that may increase the perception of coercion is the more widespread use of a court-mandated process of detention, present in many countries worldwide. It is not, however, only the process of legal detention in hospital that can lead to the subjective experience of coercive care; ${ }^{2}$ locked wards, ${ }^{3}$ physical restraint ${ }^{4}$ and out-patient commitment $^{5}$ are examples of interventions that can be seen to reduce a patient's liberty, increasing the likelihood of patients perceiving the care they receive negatively. As public policy drives an ever-more community-oriented psychiatric service, it is possible that the number of coercive actions undertaken to maintain patients in fewer hospital beds will grow, potentially increasing perceived coercions in some settings. This makes understanding coercion particularly important for practising psychiatrists. ${ }^{6}$

Coercion is the negative subjective experience of loss of autonomy caused by an involuntary action, in this case from the mental health services towards a patient. ${ }^{7}$ An objective coercive action is a necessary, but not sufficient, condition for a patient to experience coercion. ${ }^{8}$ For example, legal detention, an objectively coercive act, is necessary for a patient to subsequently feel coerced, but the use of legal detention, although objectively coercive, does not, ipso facto, engender the subjective experience of coercion. With the development of the patients' rights movement, the views of patients are becoming better understood ${ }^{9}$ and there is growing importance of allowing patients to choose their own treatment. ${ }^{10}$ This has led to developments such as nonhospital-based treatments that are more acceptable to patients and are related to reductions in perceived coercion. ${ }^{11}$ Similarly, mechanisms are being developed to ensure patients' rights are not infringed as part of psychiatric care. ${ }^{12}$

The issue of coercion as a potentially unwanted consequence of management is therefore becoming urgently important, both in terms of its impact on treatment and the need to understand the factors that influence it. This is true for intuitively coercive actions, such as detention, but also for management interventions that may not be considered coercive, such as informal admission. Despite this, the prevalence of this unwanted 'side-effect' is unclear. The aim of this review is therefore to systematically collate those papers that outline the prevalence of perceived coercion to ascertain how common this is and understand the variation in reported rates. An exploration of the factors that may increase or decrease these rates from both a methodological and an epidemiological perspective is also considered. 


\section{Method}

\section{Selection of papers}

Selection of papers into the review was kept broad to ensure all papers reporting on the experiences of patients were included. We chose papers describing adults between 16 and 65 years of age in adult psychiatric care (or coercion reported about such care). The papers had to report on the experience of coercion from the patient's perspective, rather than examining potentially coercive interventions. Papers that did not fulfil the inclusion criteria were rejected. All included papers had ethical approval.

It was decided a priori to collect information on coercion presented in a dichotomised fashion. This decision was made for three reasons. Most importantly, in this review coercion was considered as a subjective experience for a patient when reflecting on a paternalistic action. As such, patients reported it to be present or not, although the degree and nature of perceived coercion clearly varies from patient to patient, and philosophically this experience has many shades of grey. ${ }^{13}$ Second, empirically coercion tends to be reported with a bimodal distribution in studies using scalar instruments to measure coercion, usually the MacArthur Perceived Coercion Scale (MPCS) ${ }^{14}$ or coercion ladder, ${ }^{15}$ suggesting that for many patients the experience of coercion is either present or absent. Finally, this approach makes statistical analysis manageable, particularly when comparing results using different measures, and as such allows for the relative effect of a number of variables to be assessed and compared with each other as to their relative impact on the patient's experience.

The MPCS is a well-validated instrument developed by the MacArthur Research Network in America. It comprises five questions drawn from the larger Admission Experience Survey and specifically addresses the experience of perceived coercion. Each question is a true/false statement and studies tend to show a bimodal distribution with the point of difference at $2 .^{14}$ The coercion ladder is a visual analogue scale ranging usually from 1 to 10 , with the fixed ends representing 'no coercion' and 'totally coerced'. Although the instrument is somewhat different in approach, it also tends to provide bimodal data and has also been validated. ${ }^{15}$ For each paper, continuous data were dichotomised according to the authors' reported cut-off points when reported in this fashion using the MPCS or the coercion ladder. Where this was unclear, the authors were contacted and asked for clarification.

Although no specific exclusion criteria were identified at the onset of the systematic review, papers were excluded if they did not report an overall coercion figure (e.g. reporting each question of an inventory separately without reporting a combined total). For papers where coercion was not reported, but it was thought the data may exist, the authors were contacted to ask whether they could supply the data. For pragmatic reasons papers not reported in English could not be included in the analysis.

The search was conducted electronically. MEDLINE, PsycINFO and Cinahl were accessed via the EBSCO platform. The free-text key words 'coerci*', 'liberty' and 'duress' were used to identify papers on coercion and the free-text term 'psych"' was used to identify the psychiatric literature. These sets were then combined with the Boolean term 'AND'. The titles of all identified papers were read; the abstract and/or full text of any paper considered to be a possible for inclusion was read, and the references of these papers were examined to cross-reference for other potential studies.

For all included papers data were extracted on the prevalence of coercion, total numbers of patients reporting coercion, and total number of patients in the sample. To assess how the prevalence of coercion might be influenced by social and methodological factors, information was recorded (where available) on: the setting of care (inpatient or out-patient), the timing of the interview, the country in which the sample was collected, the instrument used to measure coercion and the legal status of the patients involved. The management strategy that led to coercion was in all cases either admission to hospital or provision of pharmacotherapy.

The timing of data collection and the instrument used to measure coercion are methodological variables that may conceivably influence prevalence rate. Country of study ${ }^{16}$ and patient legal status ${ }^{17}$ are epidemiological factors that could be expected to alter prevalence rates. Although treatment setting represents a common intervention potentially associated with coercion, there were only two out-patient studies (both conducted in the USA) examining this variable and these were not, therefore, included in the meta-regression.

\section{Statistical analysis}

The METAREG package implemented in Stata 10.1 for Windows ${ }^{18}$ was used to calculate overall prevalence of coercion across studies, and also meta-regression of coercion prevalence according to those explanatory variables listed earlier. Raw data from each study were used to calculate the log odds and associated standard error of being coerced. ${ }^{19}$ Two studies reported $100 \%$ coercion, and so 0.5 was added to the total denominator in these studies to allow calculation of the log odds. ${ }^{20}$

Covariates used in the meta-regression were patients' legal detention status (voluntary, legally detained, mixed sample); geographical study location (Nordic countries, USA, and other countries - UK, Switzerland, Australia and New Zealand); interview timing (less than 7 days after admission; 7 days or longer after admission); and coercion instrument used (MPCS and coercion ladder).

The meta-regression treated multiple results from the same paper as independent. For example, six papers reported separate coercion figures for legally detained and voluntarily admitted patients. A pooled odds ratio for this comparison is reported based on these papers alone for comparison with the meta-regression. Likewise, for one paper $^{21}$ data were reported from several Nordic countries which were treated as four independent samples.

\section{Results}

In total, 5032 potential papers were highlighted by the initial electronic search. After review of the titles and abstracts, 75 were considered as 'possibles' and read in full; 


\begin{tabular}{|c|c|c|c|}
\hline & Total in study, $n$ & Coerced, \% & Country \\
\hline Kjellin et al, $2006^{21}$ & 764 & 49 & Nordic countries \\
\hline Haglund et al, $2003^{22}$ & 11 & 64 & Sweden \\
\hline Priebe et al, $2009^{23}$ & 733 & 87 & UK \\
\hline Lidz et al, $1998^{24, b}$ & 171 & 22 & USA \\
\hline Swartz et al, $2003^{25}$ & 99 & 44 & USA \\
\hline Link et al, $2008^{26}$ & 184 & 51 & USA \\
\hline Hoge et al, $1997^{27}$ & 156 & 33 & USA \\
\hline Kjellin et al, $2004^{28}$ & 282 & 41 & Sweden \\
\hline Eriksson \& Westrin, $1995^{29}$ & 199 & 47 & Sweden \\
\hline Bindman et al, $2005^{30}$ & 98 & 47 & UK \\
\hline Ivar Iversen et al, $2002^{31}$ & 222 & 49 & Norway \\
\hline Soergaard, $2004^{32}$ & 190 & 16 & Norway \\
\hline Shannon, $1976^{33}$ & 100 & 48 & Australia \\
\hline Svensson \& Hansson, $1994^{34}$ & 50 & 42 & Sweden \\
\hline McKenna et al, $2003^{35}$ & 69 & 81 & New Zealand \\
\hline Kuosmanen et al, $2007^{36}$ & 51 & 69 & Finland \\
\hline Bonsack \& Borgeat, $2009^{37}$ & 91 & 74 & Switzerland \\
\hline Olfsson \& Jacobsson, $2001^{38, b}$ & 19 & 90 & Sweden \\
\hline Total sample size & 3489 & & \\
\hline
\end{tabular}

a. In-patient treatment in all studies apart from Swartz 2003 and Link 2008, where it was out-patient.

b. Prevalence rate confirmed by personal correspondence.

18 papers including 3489 patients were left for the final analysis. Total patients included by study ranged from $11^{22}$ to $733^{23}$ (Table 1).

Published raw prevalence rates of coercion varied from $22 \%^{24}$ (C. Lidz, coercion data obtained through personal communication, 2011) to $87 \% .^{23}$ Two papers from an outpatient setting reported raw prevalence rates of $44 \%^{25}$ and $51 \%,{ }^{26}$ but they are not included in the subsequent analysis. The raw combined prevalence rate was $53 \%$ (95\% CI $40-$ 65). Including the two out-patient studies gave a prevalence of $52 \%$ (95\% CI 41-63). The clearest divergence in coercion prevalence was between legally detained and informally admitted patients. The raw combined prevalence for coercion in the legally detained group was $74 \%$ (95\% CI 63-82), whereas the coercion prevalence for the informal patient group was $25 \%$ (95\% CI 20-31).

Meta-regression was undertaken to examine the effect of timing of questioning, instrument used to measure coercion, country of study and legal status (Table 2). Legal status at admission was strongly associated with perceived coercion: legally detained in-patients were more than eight times as likely as voluntarily admitted patients to experience coercion. Coercion was reported more rarely in the USA than in other Western countries in the analysis. From a methodological perspective, interview timing was not associated with significant differences in coercion with OR=1.9 (95\% CI 0.8-4.4). Finally, the instrument used to assess coercion appears to influence the prevalence of coercion: those assessed with the coercion ladder or another assessment method were less likely to report coercion than those assessed with the MPCS.
Six studies reported coercion figures for both legally detained and voluntarily admitted patients ${ }^{21,27-31}$ allowing a direct estimation of the odds ratio for experiencing coercion between these legal status groups. The pooled odds ratio calculated by meta-analysis for these studies was 8.5 (95\% CI 4.5-15.8), comparable with the odds ratio for legally detained $v$. voluntary patients in the meta-regression (Table 2).

\section{Discussion}

This paper describes how common it is for patients in psychiatric care to experience the treatment they receive as coercive and highlights the variables that may influence this. It is the first systematic review and analysis of data published in this area that allows a clear understanding of this issue. It highlights that coercion is common not only in legally detained patients, but also among patients who are in hospital of their own free will, for treatment they are presumed to have consented to.

Legally detained patients are, unsurprisingly, more likely to report coercion than those voluntarily admitted. This is both intuitive and unsurprising. Both metaregression and more straightforward meta-analysis of the odds ratio from studies where coercion data were collected in detained as well as non-detained samples make this finding clear. Legal detention plays a large part in the experience of coercion but is not the only important factor. Country of study was also a significant variable, with coercion less common in the USA, even after controlling for the relative distribution of legal detention, when 
Table 2 Odds ratios from meta-regression analysis for experiencing subjective coercion

\begin{tabular}{|c|c|c|c|}
\hline Factor & Odds ratio & $95 \% \mathrm{Cl}$ & $P$ \\
\hline $\begin{array}{l}\text { Legal status of admission } \\
\text { Detained } \\
\text { Mixture of detained and informal } \\
\text { Informal }\end{array}$ & $\begin{array}{c}8.6 \\
3.1 \\
\text { Reference }^{b}\end{array}$ & $\begin{array}{l}4.6-15.9 \\
1.4-6.9\end{array}$ & $\begin{array}{r}<0.001 \\
0.008\end{array}$ \\
\hline $\begin{array}{l}\text { Timing of interview } \\
7 \text { days or longer, or mixed } \\
\text { Less than } 7 \text { days }\end{array}$ & $\begin{array}{c}1.9 \\
\text { Reference }^{b}\end{array}$ & $0.8-4.4$ & 0.148 \\
\hline $\begin{array}{l}\text { Country } \\
\text { Nordic countries } \\
\text { Other countries } \\
\text { USA }\end{array}$ & $\begin{array}{c}3.3 \\
5.6 \\
\text { Reference }^{b}\end{array}$ & $\begin{array}{l}1.3-8.4 \\
2.1-15.2\end{array}$ & $\begin{array}{l}0.016 \\
0.002\end{array}$ \\
\hline $\begin{array}{l}\text { Instrument used to assess coercion } \\
\text { Coercion ladder or other instrument } \\
\text { MPCS }\end{array}$ & $\begin{array}{c}0.4 \\
\text { Reference }^{b}\end{array}$ & $0.2-0.9$ & 0.03 \\
\hline
\end{tabular}

MPCS, MacArthur Perceived Coercion Scale.

a. UK, Switzerland, Australia and New Zealand.

b. Reference denotes reference level against which odds ratios were calculated for factor.

compared with both Nordic countries and the UK and other countries in this review. It is unclear what factors may be influencing this, although the variation is significant and warrants closer examination. The EUNOMIA project, ${ }^{39}$ funded by the European Commission, is exploring the cross-national variation in Europe and may address some of these questions, although cultural factors including patient expectation, legislation and psychiatric practice are likely to be important variables. Recent research suggests some measures of social pressure vary by country, ${ }^{40}$ with increased pressure ('leverage') applied in a US setting. This highlights the importance of clearly defining the construct examined, in this case coercion as opposed to leverage, and how these are defined. Szmukler \& Applebaum have highlighted the issues in the need for clarity in this area, ${ }^{13}$ identifying the coercive 'hierarchy' and where coercion sits in this. Our study examines papers at the most coerced end of this hierarchy and this potentially explained the differences found in this meta-analysis compared with the individual study of Szmukler \& Applebaum. Our study also grouped European studies together, in much the same fashion as the EUNOMIA study. Although this increases statistical power, it may weaken the generalisability of the finding to particular patient groups. A combination of meta-analysis and individual studies is likely to prove the most balanced understanding of perceived coercion to guide clinical practice.

The period in which information on coercion was collected from patients appeared to have little influence on the experience of coercion, suggesting that there is no reporting bias for coercive experiences at the early stages of treatment compared with the later stages. This is surprising as recall bias may reinforce affective memory of interventions, enhancing them in a patient's mind. From a research perspective, this suggests there is no pressure to collect information about coercion from patients with any particular speed following a particular intervention and this may be of value in the design of future studies.

The tool used to measure coercion appeared to have an impact on prevalence: studies using the MPCS were associated with higher prevalence rates than studies using the coercion ladder or some other method of assessing coercion. This may reflect the wider scope of the MPCS than a visual analogue scale of the coercion ladder or a simple yes/no response. The MPCS is a well-validated, peerreviewed tool which clearly measures subjective experience in a reproducible way, with good interrater reliability. It may be that this tool also measures other constructs, such as threats and social leverage, and this may explain greater prevalence rates. ${ }^{24}$ Nonetheless, having a scientifically validated tool improves rigour in studying this potentially vague concept and allows for combination of findings to provide for a greater understanding of this experience as is presented in this paper. Such variation does, however, suggest that a single tool be used when measuring this subjective experience to improve reliability of coercion as a construct.

\section{Limitations}

These findings are limited by several factors. First, to examine the subjective experience of coercion, all papers with purely objective definitions of coercion (such as legal detention) were excluded. Although this ignores some evidence on coercion, it increases the robustness of the findings by examining one construct - the patient's experience. This minimises the problems of heterogeneity that diminish the usefulness of many systematic reviews. Second, all of the studies included in this review came from predominantly White, Western, high-income countries. This potentially reduces the generalisability of these findings to low- and middle-income countries or countries with vastly different legal or social milieus. Similarly, the majority of papers examined in-patients within a public health system, again limiting the generalisability of these findings to outpatient or private clinic settings. It was not possible to accurately describe the in-patient setting for each study included, although it is worth noting the papers from highincome Western countries may improve the similarity of the setting examined. It is also worth noting all included papers were from general adult settings, as opposed to forensic or child settings, which again was designed to improve the 
similarity of the environmental influences. Despite this, it is possible that unaccounted for environmental changes may have led to counterintuitive findings and need to be considered as a limitation to the finding of this study. These limitations do, however, improve the homogeneity of the populations studied, improving the robustness of the findings within this group. Limitation to English language papers may have excluded some potential articles, although only German and Spanish language papers were found in the review process and overlooked on the basis of language, not papers from Africa, Asia or South America.

From a statistical perspective, the study design for the meta-analysis is essentially observational, in that the studies are not randomised to the different levels of the explanatory factors. In line with standard epidemiological thinking, evidence from the meta-regression is therefore less reliable than evidence from a study where multiple factors are assessed within a single unifying methodological approach. The risk in meta-regression is that the results described might be attributable to residual confounding of the factors of interest with some unknown factor. ${ }^{41}$ This would, however, be unlikely in this analysis owing to the magnitude of the odds ratios found for several factors.

\section{Implications for practitioners and patients}

The findings of this systematic review and meta-analysis raise important issues for clinical in-patient mental health workers, researchers in the field, public policy makers and patients.

For clinicians, the finding that one in four voluntarily admitted in-patients experience coercion in management has ethical implications for practice. It would suggest that clarity around the issues of explicit consent for interventions is important and that implied consent, on the basis of voluntary status, may be misplaced. It also reminds clinicians that experiences of coercion are common for many in-patients, and need to be reflected on within in-patient treatment teams to ensure that practices that reduce coercion are regularly applied. ${ }^{42}$

For researchers, the need for clarity about the construct under investigation is important and the use of a common tool, such as the MPCS, improves this. Timing of data collection seems less relevant. Future reviews will benefit from authors reporting on issues regarding those factors that appear to influence coercion rates, particularly common interventions (e.g. in-patient $v$. out-patient care) and demographic features. In this review, only legal detention has sufficient data to allow such analysis and the finding of increased coercion is not surprising.

For public policy and lawmakers, this systematic review serves as a timely reminder that intuition may not be correct. Much of the experience of coercion is in relation to social constructs, commonly the law, and its revision is not under medical control. The interactions between psychiatrists and patients are necessarily governed by broader cultural factors. The very high rate of coercion in some cultural settings needs further examination to elicit what specific factors are associated with it. This type of analysis allows for evidence-based changes in healthcare systems that can potentially improve perceptions of healthcare and may reduce the stigma associated with mental disorders both within and without the psychiatric profession. $^{43}$

For patients, this review highlights the complex nature of mental health interactions and the importance of patients' subjective experiences. In-patient treatment is neither easy nor straightforward, and balancing the need for state-of-the-art care, cultural reality and patient choice is, clearly, fraught with difficulty. ${ }^{44}$ Many of the decisions made may be felt as coercive ${ }^{45}$ and the challenge for psychiatric in-patient care is to continuously improve, through research and practice, to optimise the patient's experience.

\section{Acknowledgements}

We thank Professors S. Priebe, C. Lidz, H. Poulsen and B. Oloffsen for answering queries about their published work and Viv Kerr and the team at the library in the Hawke's Bay District Health Board (New Zealand) for their assistance.

\section{About the authors}

Giles Newton-Howes is a consultant psychiatrist at Hawkes Bay District Health Board, New Zealand, honorary senior lecturer at Imperial College London, UK, and honorary clinical lecturer at Wellington School of Medicine, Otago University, Napier, New Zealand; James Stanley is senior research fellow and biostatistician, Wellington School of Medicine, Otago University, Wellington, New Zealand.

\section{References}

1 Salize HJ, Dressing H. Epidemiology of involuntary placement of mentally ill people across the European Union. Br J Psychiatry 2004; 184: $163-8$.

2 Katsakou C, Priebe S. Outcome of involuntary hospital admission - a review. Acta Psychiatr Scand 2006; 114: 232-41.

3 Haglund K, Von Essen L. Locked entrance doors at psychiatric wards advantages and disadvantages according to voluntarily admitted patients. Nord J Psychiatry 2005; 59: 511-5.

4 Sailas EES, Fenton M. Seclusion and restraint for people with serious mental illnesses. Cochrane Database Syst Rev 2000; 1: CD001163.

5 Swartz MS, Wagner HR, Swanson JW, Hiday VA, Burns BJ. The perceived coerciveness of involuntary outpatient commitment: findings from an experimental study. J Am Acad Psychiatry Law 2002; 30: 207-17.

6 Zinkler M, Priebe S. Detention of the mentally ill in Europe - a review. Acta Psychiatr Scand 2002; 106: 3-8.

7 Rhodes M. The nature of coercion. J Value Inq 2000; 34: 369-81.

8 Newton-Howes G. Coercion in psychiatric care: where are we now, what do we know, where do we go? Psychiatrist 2010; 34: 217-20.

9 Glass C, Arnkoff D. Consumers' perspectives on helpful and hindering factors in mental health treatment. J Clin Psychol 2000; 56: 1467-80.

10 Nilstun T, Syse A. The right to accept and the right to refuse. Acta Psychiatr Scand 2000; 101 (suppl): 31-4.

11 Gliburt H, Slade M, Rose D, Lloyd-Evans B, Johnson S, Osborn DPJ Service users' experiences of residential alternatives to standard acute wards: qualitative study of similarities and differences. $\mathrm{Br} J$ Psychiatry 2010; 197 (suppl 53): s26-31.

12 Department of Health. Deprivation of Liberty Safeguards: Code of Practice to Supplement the Main Mental Capacity Act 2005 Code of Practice. TSO (The Stationery Office), 2008.

13 Szmukler G, Applebaum PS. Treatment pressures, leverage, coercion and compulsion in mental health care. J Ment Health 2008; 17: 233-44. 
14 MacArthur Research Network on Mental Health and the Law. The MacArthur Coercion Study: May 2004 Update of the Executive Summary. MacArthur Research Network, 2004 (http://www.macarthur.virginia. edu/coercion.html)

15 Høyer G, Kjellin L, Engberg M, Kaltiala-Heino R, Nilstun T, Sigurjónsdóttir $\mathrm{M}$, et al. Paternalism and autonomy: a presentation of a Nordic study on the use of coercion in the mental care system. Int $\rfloor$ Law Psychiatry 2002; 25: 93-108.

16 Bergk J, Flammer E, Steinert T. Ratings of coercive interventions by inpatients and staff in Germany. Psychiatr Serv 2009; 60: 1401-2.

17 Allen M, Smith V. Opening Pandora's box: the practical and legal dangers of involuntary outpatient commitment. Psychiatr Serv 2001; 52: 342-6.

18 Harbord R, Higgins J. METAREG: Stata Module to Perform Meta-analysis Regression. Boston College Department of Economics, 2004.

19 Clayton D, Hills M. Statistical Models in Epidemiology. Oxford University Press, 1993.

20 Thompson S, Sharps S. Explaining heterogeneity in meta-analysis: a comparison of methods. Stat Med 1999; 18: 2693-708.

21 Kjellin L, Høyer G, Engberg M, Kaltiala-Heino R, Sigurjónsdóttir M. Differences in perceived coercion at admission to psychiatric hospitals in the Nordic countries. Soc Psychiatry Psychiat Epidemiol 2006; 41 241-7.

22 Haglund K, Von Knorring L, Von Essen L. Forced medication in psychiatric care: patient experiences and nurse perceptions. J Psychiatr Ment Health Nurs 2003; 10: 65-72.

23 Priebe S, Katsakou C, Amos T, Leese M, Morriss R, Rose D, et al. Patients' views and readmissions 1 year after involuntary hospitalisation. Br J Psychiatry 2009; 194: 49-54

24 Lidz CW, Mulvey EP, Hoge SK, Kirsch BL, Monahan J, Eisenberg M, et al. Factual sources of psychiatric patients' perceptions of coercion in the hospital admission process. Am J Psychiatry 1998; 155: 1254-60.

25 Swartz M, Swanson J, Hannon M. Does fear of coercion keep people away from mental health treatment? Evidence from a survey of persons with schizophrenia and mental health professionals. Behav Sci Law 2003; 21: 459-72.

26 Link B, Castilled D, Stuber J. Stigma and coercion in the context of outpatient treatment for people with mental illness. Soc Sci Med 2008; 67: 409-19.

27 Hoge SK, Lidz CW, Eisenberg M, Gardner W, Monahan J, Mulvey E, et al. Perception of coercion in the admission of voluntary and involuntary psychiatric patients. Int J Law Psychiatry 1997; 20: 167-81.

28 Kjellin L, Andersson K, Bartholdson E, Candefjord IL, Holmstrøm H, Jacobsson $L$, et al. Coercion in psychiatric care - patients' and relatives' experiences from four Swedish psychiatric services. Nord J Psychiatry 2004; 58: 153-9.
29 Eriksson K, Westrin C-G. Coercive measures in psychiatric care. Acta Psychiatr Scand 1995; 92: 225-30.

30 Bindman J, Reid Y, Szmukler G, Tiller J, Thornicroft G, Leese M Perceived coercion at admission to psychiatric hospital and engagement with follow-up: a cohort study. Soc Psychiatry Psychiatr Epidemiol 2005; 40: 160-6.

31 Ivar Iversen K, Høyer G, Sexton H, Grønli OK. Perceived coercion among patients admitted to acute wards in Norway. Nord J Psychiatry 2002; 56: 433-9.

32 Soergaard K. Patients' perception of coercion on acute psychiatric wards: an interview study. Nord J Psychiatry 2004; 58: 299-304.

33 Shannon P. Coercion and compulsory hospitalization: some patients' attitudes. Med J Aust 1976; 2: 798-800.

34 Svensson B, Hansson N. Patients satisfaction with inpatient psychiatric care. Acta Psychiatr Scand 1994; 90: 379-84.

35 McKenna B, Simpson A, Coverdale J. Patients' perceptions of coercion on admission to forensic psychiatric hospital: a comparison study. Int J Law Psychiatry 2003; 26: 355-72.

36 Kousmanen L, Hätönen $H$, Malkavaara $H$, Kylmä J, Välimäki M. Deprivation of liberty in psychiatric hospital care: the patient's perspective. Nurs Ethics 2007; 14: 597-607.

37 Bonsack C, Borgeat F. Perceived coercion and need for hospitalization related to psychiatric admission. Int J Law Psychiatry 2005; 28: 342-7.

38 Olofsson B, Jacobsson N. A plea for respect: involuntarily hospitalized psychiatric patients' narratives about being subjected to coercion J Psychiatr Ment Health Nurs 2001; 8: 357-66.

39 Kallert T, Glöckner M, Onchev G, Raboch J, Karastergiou A, Solomon Z, et al. The EUNOMIA project on coercion in psychiatry: study design and preliminary data. World Psychiatry 2005; 4: 168-72.

40 Burns T, Yeeles $K$, Molodynski A, Nightingale $H$, Vazquez-Montes $M$ Sheehan K, et al. Pressure to adhere to treatment ('leverage') in English mental healthcare. Br J Psychiatry 2011; 199: 145-50.

41 Thompson S, Higgins J. How should meta-regression analyses be undertaken and interpreted? Stat Med 2002; 21: 1559-73.

$42 \mathrm{Lidz} C$. Coercion in psychiatric care: what have we learned from research? J Am Acad Psychiatry Law 1998; 26: 631-7.

43 Newton-Howes G, Weaver T, Tyrer P. Attitudes of staff towards patients with personality disorder in community mental health teams. Aust N Z J Psychiatry 2008; 42: 572-7.

44 Olsen C. Towards an ethical standard for coerced mental health treatment: least restrictive or most therapeutic? J Clin Ethics 1998; 9 235-46.

45 Newton-Howes G, Mullen R. Coercion in psychiatric care: systematic review of correlations and themes. Psychiatr Serv 2011; 62: 465-70. 